\title{
IN-CAM Outcomes Database: Its Relevance and Application in Massage Therapy Research and Practice
}

Ania Kania, RMT, BSc*; Marja J. Verhoef, PhD*; Trish Dryden, RMT, MEd ${ }^{\dagger}$; Mark A. Ware, $\mathrm{MD}, \mathrm{MRCP}(\mathrm{UK}), \mathrm{MSc}$ *

Department of Community Health Sciences, *University of Calgary, Calgary, AB, Canada; Applied Research Center, Centennial College, ${ }^{\dagger}$ Toronto, ON, Canada; Department of Anesthesia, ${ }^{*}$ McGill University, Montreal, QC, Canada

One of the most commonly used complementary and alternative medicine (CAM) modalities in North America is massage therapy (MT). Research to date indicates many potential health benefits of MT, suggesting that ongoing research efforts to further elucidate and substantiate preliminary findings within the massage profession should be given high priority. Central to the development of a sound evidence base for MT are the use of valid, reliable, and relevant outcome measures in research, and practice in assessing the effectiveness of MT. The purpose of the present article is to introduce MT researchers and massage therapists interested in using outcome measures in research and clinical practice to the IN-CAM Outcomes Database website by describing the Outcomes Database and identifying its utility in MT research and practice. The IN-CAM Outcomes Database is a centralized location where information on outcome measures is collected and made accessible to users. Outcome measures are organized in the database within the Framework of Outcome Domains. The Framework includes health domains relevant to conventional medicine and $\mathrm{CAM}$ alike, and health domains that have been identified as important to CAM interventions. Users of the website may search for information on a specific outcome measure, plan research projects, and engage in discussions related to outcomes assessment in the CAM field with other users and with members of the CAM research community. As the MT profession continues to evolve and move toward evidence-informed practice, the IN-CAM Outcomes Database website can be a valuable resource for MT researchers and massage therapists.

KEYWORDS: Massage therapy, research, practice, health outcomes, outcomes database

\section{INTRODUCTION}

One of the most commonly used complementary and alternative medicine (CAM) modalities in North America is massage therapy $(\mathrm{MT})^{(1,2)}$. Increasingly,
MT is part of a comprehensive treatment approach in various health care settings, from private health clinics to hospitals. Massage therapy is used for a wide range of health-related reasons - from treatment of various symptoms and conditions to prevention and health maintenance ${ }^{(3-5)}$. Research to date indicates many potential health benefits of MT, suggesting that ongoing research efforts to further elucidate and substantiate preliminary findings within the massage profession should be given high priority.

Central to the development of a sound evidence base for MT are the use of valid, reliable, and relevant outcome measures in research, and practice in evaluating massage therapy interventions. Currently, the outcome measures used in both the health and the social sciences are many and varied. They also vary widely in terms of target outcome, length, format, target population, and degree of specificity ${ }^{(6)}$. A number of resources have been developed to provide overviews of outcome measures for example, the Patient-Reported Outcomes Measurement Information System (PROMIS) and the Patient-Reported Outcome and Quality of Life Instruments Database (PROQOLID) - but these resources often lack the types of outcomes that are relevant to CAM interventions. Furthermore, knowledge of, access to, and time required in searching for appropriate outcome measures is often a barrier to the implementation of outcome measures, particularly in practice settings. The development of the IN-CAM Outcomes Database (the Database) (http://www.outcomesdatabase.org) aims to address this gap. Because MT is currently classified as a CAM modality ${ }^{(7)}$, the purpose of the present article is to introduce MT researchers and massage therapists interested in using outcome measures in research and clinical practice to the IN-CAM Outcomes Database website by

- describing the Database, and

- identifying its utility in MT research and practice.

\section{THE IN-CAM OUTCOMES DATABASE}

The Canadian Interdisciplinary Network for Complementary and Alternative Medicine Research (IN-CAM) is an interdisciplinary network of researchers, 
practitioners, educators, and policymakers interested in advancing the field of CAM and integrative health care research. Its primary aims ${ }^{(8)}$ are

- to foster a sustainable, collaborative and highly trained CAM research community; and

- to facilitate, support, and build CAM research capacity in the areas of CAM effectiveness, efficacy, and safety and CAM health care delivery and policy.

In 2005, at an IN-CAM strategic planning meeting, it was determined that easier access to a wide range of outcomes relevant to CAM research was a priority issue $^{(9)}$. In response, the open-access IN-CAM Outcomes Database was created ${ }^{(10)}$. The Database is designed to be a resource for researchers and practitioners in CAM fields such as MT on outcome measures, and a forum in which issues related to outcome measures and assessment of CAM outcomes can be communicated and discussed.

The Database is a centralized location in which information concerning outcomes measures is collected and made accessible to users. Information on each outcome measure includes

- a description of the outcome measure,

- the number of questions (items) contained in the measure,

- a sample item,

- the target population,

- the time required to administer the measure,

- how the measure is administered,

- a list of languages into which the measure has been translated,

- links and contacts to access or obtain the outcome measure, and

- the cost (if any) to obtain the outcome measure.

Ideally, only well-designed, valid, and reliable measures are used in research and practice. Therefore, if an outcome measure has been psychometrically tested, the key psychometric references are provided. To facilitate comparisons of findings across studies, references for CAM studies that have used the outcome measure are also provided. It is the responsibility of the user of the Database to be familiar with the qualities and characteristics that are required of an outcome measure and how to appraise those aspects of a measure so as to select the most appropriate measure for the project at hand. To assist users in this process, particularly novice researchers or practitioners undertaking research within their practices, a Glossary of Terms and commentary on Attributes of a Good Outcome Measure are available on the Database website.

\section{THE FRAMEWORK}

All outcome measures in the Database are categorized or classified within the Framework of Outcome
Domains (Fig. 1). During the development of the IN-CAM Outcomes Database, a need became apparent not only to create a central access point for information on outcome measures, but to also to categorize outcome measures within a framework that captures the various health domains that are relevant to CAM interventions and the components that affect the effectiveness of care provided.

The Framework of Outcome Domains has 9 domains (Fig. 1, Table 1). Of these 9 domains, 4 (physical, psychological, social, and quality of life) contain outcomes that are relevant in conventional medicine as well as CAM. However, given the distinct healing philosophies and outcomes of CAM interventions, it was recognized that a broader range of outcome measures had to be considered. Therefore, 5 additional domains were identified as unique and important to CAM and were included in the Framework.

\section{Spiritual Health}

Spiritual health or well-being is often distinguished from physical and emotional health, and is acknowledged in many CAM practices as an important component of health.

\section{Holistic}

The holistic domain represents a global level of wellbeing, reflecting a unique outcome that cannot be calculated by summing outcomes in the physical, psychological, social, and quality of life domains.

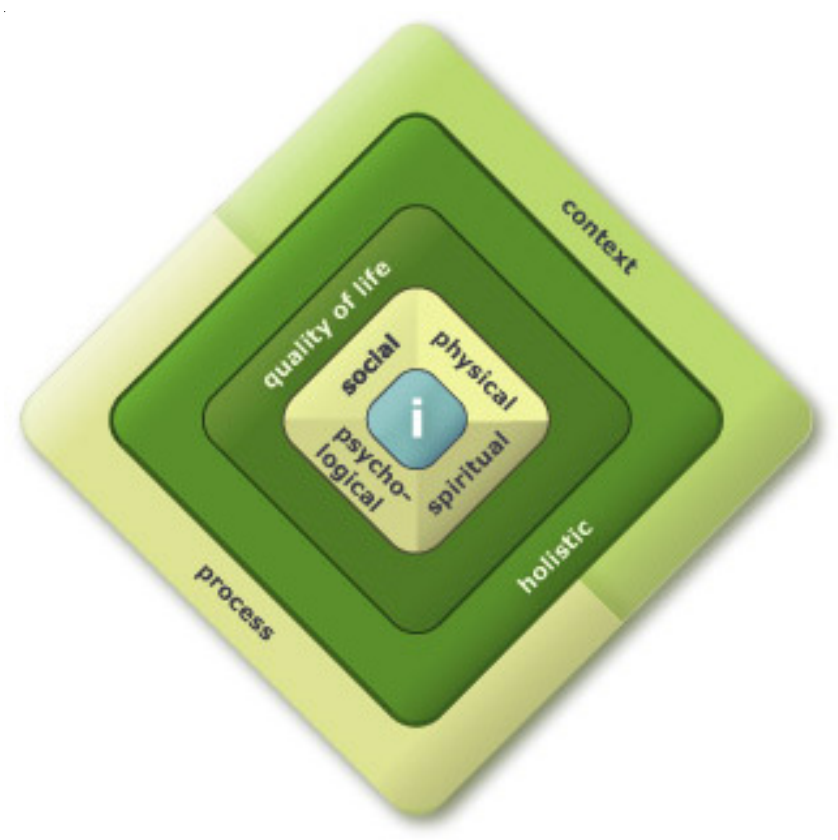

FIGURE 1. Framework of Outcome Domains from the IN-CAM Outcomes Database. 
TABLE 1 Domains Incorporated into the Framework of Outcome Domains

\begin{tabular}{|c|c|}
\hline Domain & Description \\
\hline Holistic & $\begin{array}{l}\text { Includes measures that assess outcomes on a global level. Encompasses each of the other domains in this database } \\
\text { simultaneously. Holistic outcomes are greater than the sum of the component parts. }\end{array}$ \\
\hline $\begin{array}{l}\text { Context of the } \\
\text { Intervention }\end{array}$ & $\begin{array}{l}\text { Includes measures that assess the set of circumstances encompassing the intervention or healing experience, such as } \\
\text { the patient-provider relationship. Contextual issues, although not outcomes per se, may affect the healing experience } \\
\text { and, thus, patient outcomes. }\end{array}$ \\
\hline $\begin{array}{l}\text { Process of the } \\
\text { Intervention }\end{array}$ & $\begin{array}{l}\text { Includes measures that assess factors related to the process of healing and personal transformation, such as learning, } \\
\text { personal growth, and enablement. Although not outcomes per se, process-related factors may have an effect on } \\
\text { patient outcomes. }\end{array}$ \\
\hline Quality of life & $\begin{array}{l}\text { Includes measures that assess quality of life, which is a difficult concept to define. For the purposes of this } \\
\text { database, quality of life outcome measures are defined as those that assess any two of physical, psychological, } \\
\text { social, or spiritual outcomes. If an outcome measure is labeled "quality of life," but addresses only one of the } \\
\text { foregoing domains, it will be found within the relevant domain. }\end{array}$ \\
\hline Spiritual & Includes measures that assess outcomes related to the spirit or soul, as distinguished from the physical self. \\
\hline Social & $\begin{array}{l}\text { Includes measures that assess outcomes related to the life and relationships of humans in their community. Measures } \\
\text { that assess spiritual behavior, but not spiritual beliefs, are included in this domain. }\end{array}$ \\
\hline Psychological & Includes measures that assess outcomes related to the mind, emotions, or other mental phenomena. \\
\hline Physical & Includes measures that assess outcomes related to the body, as distinguished from the mind or spirit. \\
\hline Individualized & $\begin{array}{l}\text { Includes measures that assess outcomes identified by the individual patient or research participant. Although these } \\
\text { measures can assess the content of the outcomes in any of the other domains, this domain captures the specific } \\
\text { nature of each individual's specific symptoms or goals. }\end{array}$ \\
\hline
\end{tabular}

\section{Individualized}

The individualized domain does not include measures with outcomes that are predefined or specified in advance. Rather, the outcomes are defined based on concerns or treatment goals identified by the individual receiving the intervention. Although these goals may fit into any or all of the other domains, individualized outcomes tend to be highly specific to the individual and are combined in ways that differ from the outcomes identified in the other domains; it is the patient rather than the investigator who decides how these outcomes should be expressed.

The unique nature of such outcomes has been recognized in the literature, and several relevant outcome measures have been developed. For example, the Measure Your Own Medical Profile (MYMOP) is an individualized ("patient-generated") instrument that aims to measure the outcomes that the patient has identified as being most important ${ }^{(11-13)}$. Health care interventions do not occur in isolation.

\section{Context and Process of the Intervention}

It is recognized that the effectiveness or impact of an intervention is affected (directly or indirectly) by the processes and the context of the intervention.
Therefore, although process and context of an intervention are not outcomes per se, they have an important effect on outcomes. As such, they are included in the Framework and situated so as to represent the concept that all outcomes in any of the other domains are influenced by process and context ${ }^{(6)}$.

\section{HIGHLIGHTING OUTCOME MEASURES UNIQUE TO CAM}

As noted earlier, given the unique health perspective and attributes of CAM interventions, there is a need to consider a broader range of outcome measures so as to capture the outcomes of those interventions. Therefore, in addition to conventional health outcome measures that are appropriate to CAM research, a key goal of the Database is to highlight and include outcome measures that are specific to CAM interventions and that are developed to measure concepts that have been identified as important outcomes of CAM interventions, such as transformation and unstuckness. For example, specific to the MT field, Moyer and Rounds developed the Attitudes Towards Massage (ATOM) scale(14). The ATOM scale aims to assess the overall attitude of individuals toward massage based on two key attitudes: massage as 
"helpful," and massage as "pleasant." An example of an outcome measure currently under development aimed at measuring the concept of transformation is the Measure Your Own Transformative Outcome Profile (by Sutherland and Ritenbaugh) ${ }^{(16)}$. This outcome measure assesses the effect and duration of an intervention on transformative change experienced by the participant. Although this measure is not yet available, it is an example of the work being undertaken by researchers to develop standardized ways of measuring important outcomes of CAM interventions.

\section{Searching for an Outcome Measure}

The Database can be accessed four ways to find a specific outcome measure. If the name of the outcome measure is known, then the measure can be located by browsing alphabetically (Fig. 2). The quick search (Fig. 3) and advanced search (Fig. 4) functions can be used to find an outcome measure based on keywords, a title, or specific information about the measure. Browsing by domain generates and displays a list of outcome measures applicable and relevant to that domain (Fig. 5).

In Table 2, a practice-based scenario shows how the Database website can be used to locate an outcome measure of interest.

Not all outcome measures are designed to be used in the same way. Clinical outcome measures are intended to assess the effectiveness of an intervention at the individual level; research outcome measures are designed to determine effectiveness at the population level. Some outcome measures require that the person administering the measure have specific qualifications. For example, it is recommended that the COOP Wonca Charts, used to measure functional capacity, be administered by a nurse, physician, or medical assis$\tan \mathrm{t}^{(19)}$. Interpretation or analysis of scores obtained from responses to items or questions in the outcome measures may also require specific credentials.

To ensure relevance to massage practice, it is important that all items or questions in the outcome measure be reviewed before administration. Although issues related to the decision-making process in the selection of appropriate outcome measures are beyond the scope of this article, practitioners and researchers need to take into consideration these distinctions and ensure that a given outcome measure is relevant in context of their clinical practice or research project.

\section{Facilitating Planning of Research Projects}

Broadly, research outcomes are those that help to assess the effectiveness of an intervention at a population level. Clinical outcomes help to assess the effectiveness of an intervention for an individual patient. Some measures are designed for diagnostic purposes to help identify health problems in a clinical setting (for example, the Beck Depression Inventory), but may

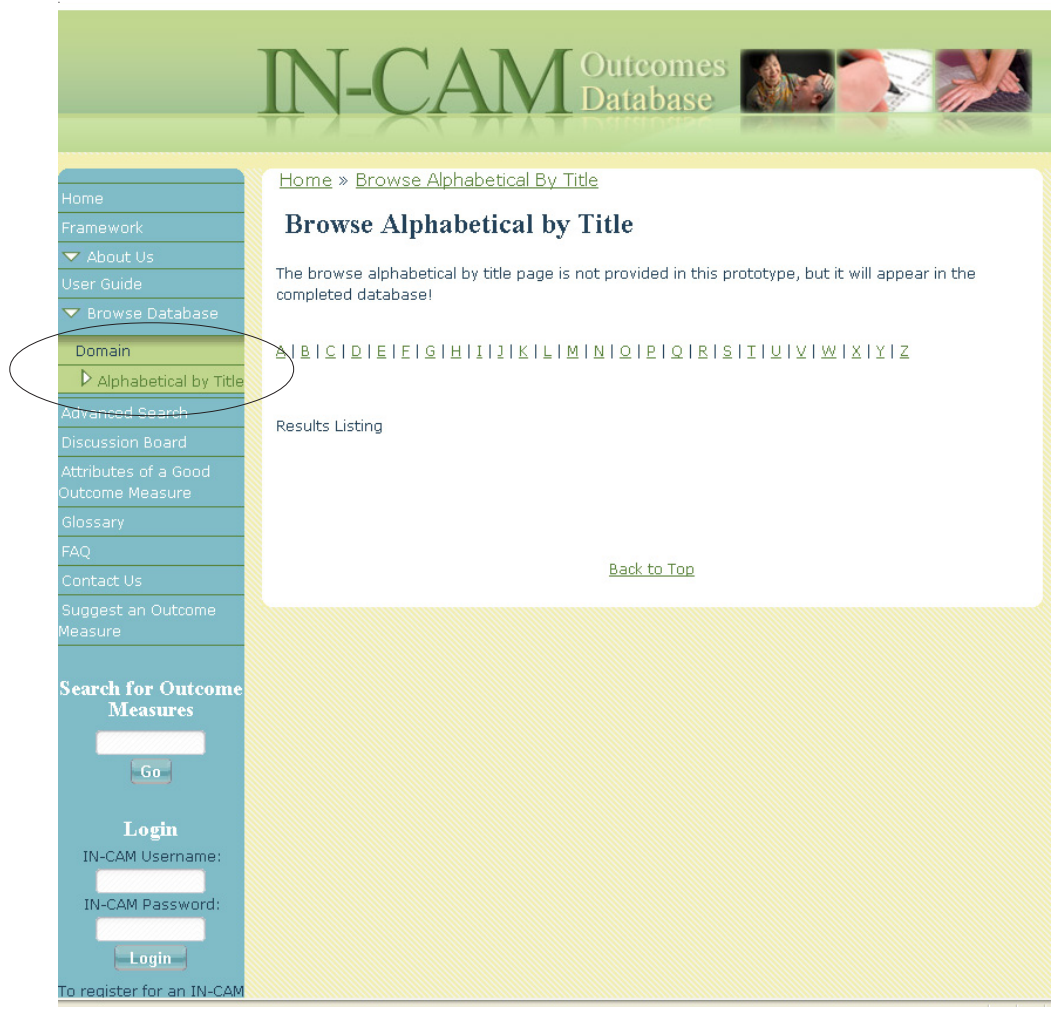

FIGURE 2. Browsing alphabetically for outcome measures in the IN-CAM Outcomes Database. 


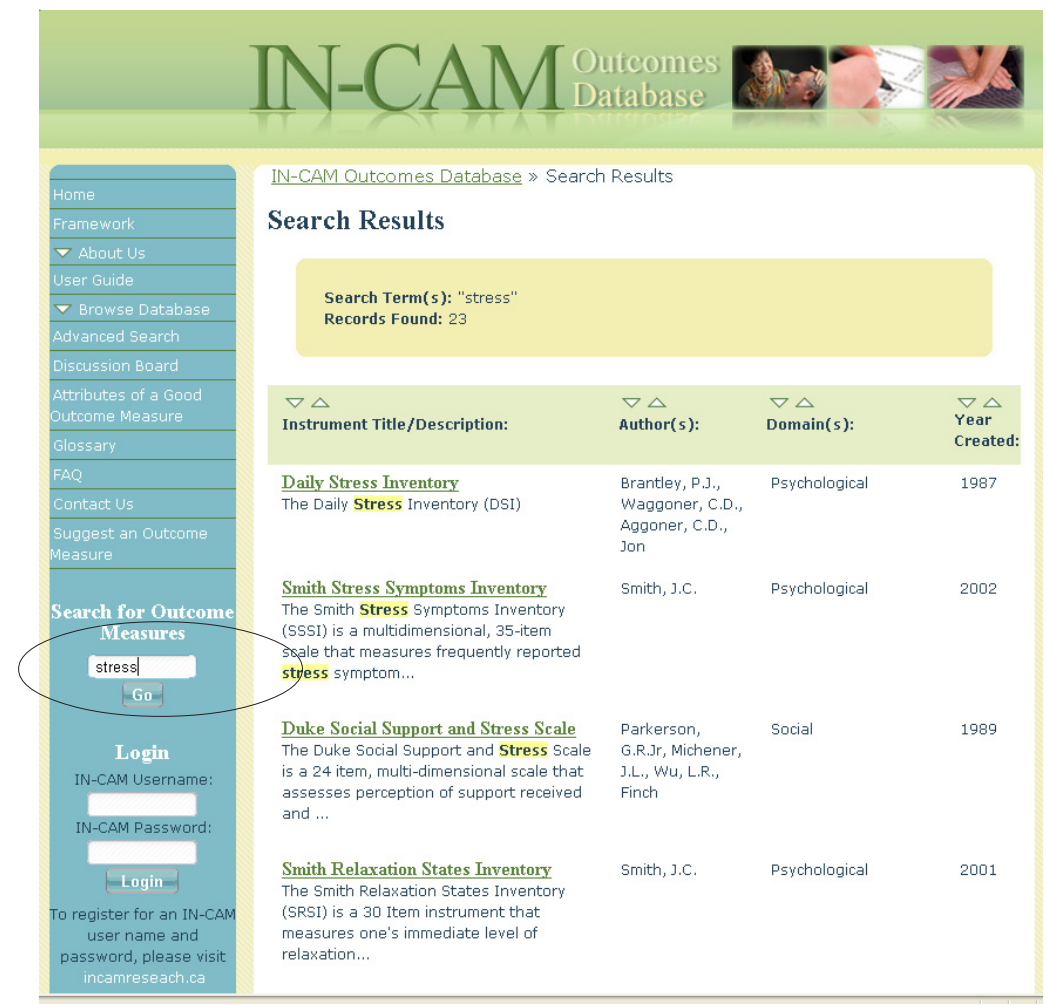

FIGURE 3. Using the quick search function to find outcome measures in the IN-CAM Outcomes Database.

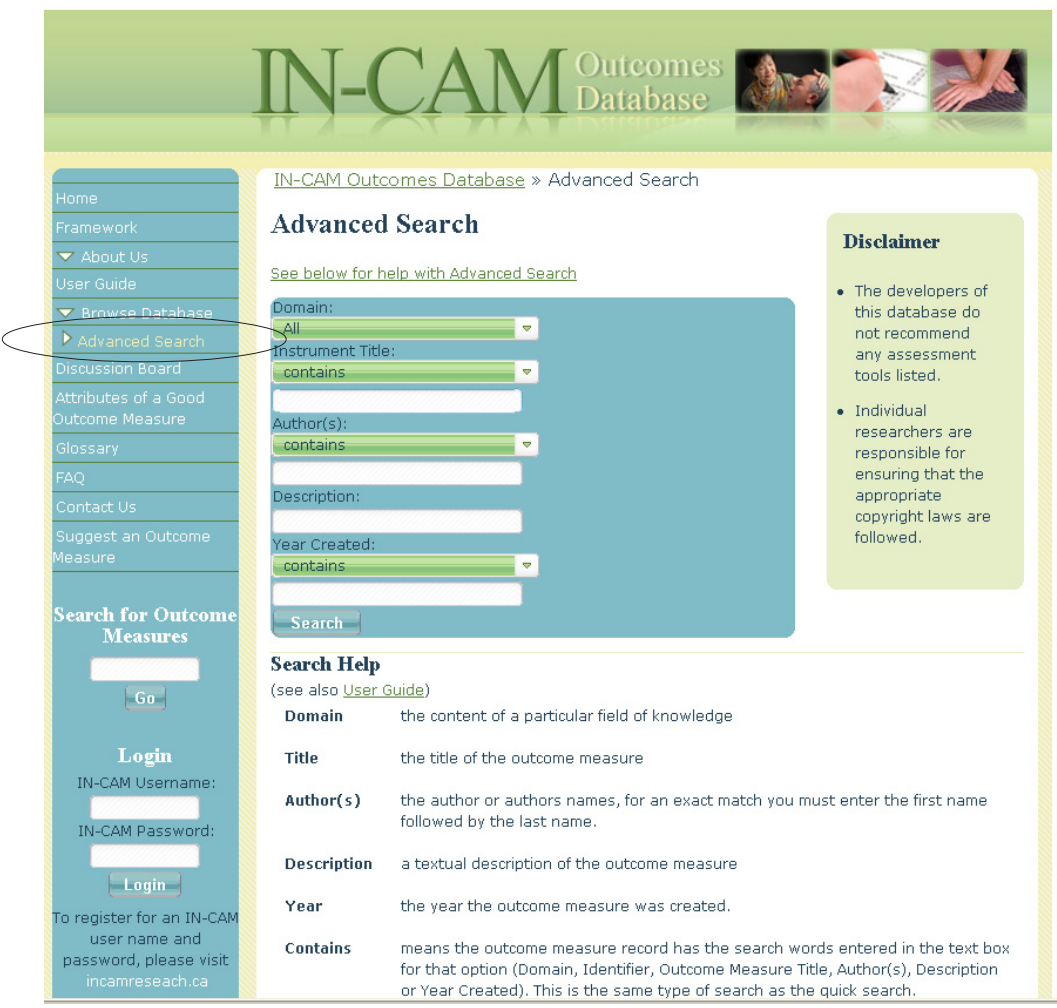

FIGURE 4. Using the advanced search function to find outcome measures in the IN-CAM Outcomes Database. 


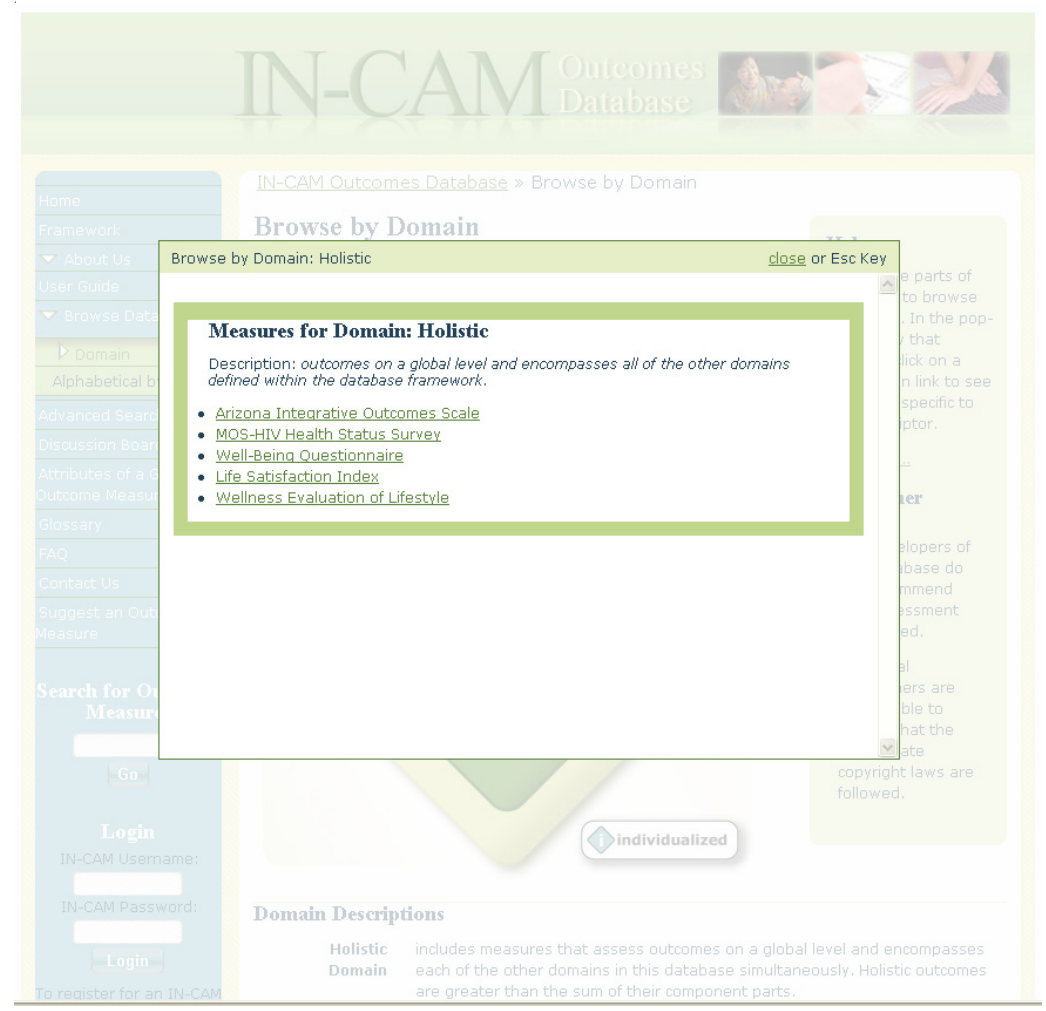

FIGURE 5. Browsing by domain for outcome measures in the IN-CAM Outcomes Database.

TABLE 2 Example: Searching for Relevant Outcome Measures

A massage therapist is treating a client who was referred by his family doctor for reduction of work-related stress. In assessing the effect of the massage treatments on the client's stress levels, the massage therapist could ask the client at the beginning and end of each treatment, "So, how are you feeling? How are your stress levels since last time you had a massage?" However, this approach may not provide reliable information and may change for each patient and each situation. The massage therapist decides to consult the IN-CAM Outcomes Database to identify validated outcome measures that assess stress reduction. Conducting a quick search using the term "stress" (Fig. 2), the massage therapist is able to locate several outcome measures such as the Daily Stress Inventory ${ }^{(16)}$.

Recognizing that stress can have negative effects on a person's physical and emotional health as well, the massage therapist is also interested in assessing the global or general well-being of this client. Browsing in the holistic domain (Fig. 5), a number of potentially useful outcome measures such as the Arizona Integrative Outcomes Scale ${ }^{(17)}$ or the Wellness Evaluation of Lifestyle ${ }^{(18)}$ are identified.

Clicking on the link to each outcome measure, the therapist reviews the information provided under basic and extended details (Fig. 6). Scanning the information provided, the massage therapist evaluates the differences between the measures and the complementary and alternative medicine studies in which they have been applied, and then determines which measure would be most suitable for capturing the experience of stress and overall well-being reported by the client. By collecting information in a standardized way using validated outcome measures, the massage therapist is able to monitor the effect of the massage treatments and the progress made by the client, and to clearly report the outcomes of the massage therapy intervention to the referring doctor.

also be used to establish inclusion criteria in a research setting. Other measures are used almost exclusively to determine the effectiveness of an intervention in a research capacity (the Profile of Mood States, for instance). Health care workers who are not involved in research should be aware of the measure type so that they can interpret research findings for clinical relevance. To ensure clinical relevance, researchers should know the strengths, limitations, and validity of the tools used in their studies.
A useful organizational tool, the Framework is also effective for raising awareness of the various domains through which CAM interventions affect the multiple dimensions of an individual's life and health. Research evaluating CAM interventions often requires the selection of a range of outcome measures to capture the complexity and individualized nature of the intervention. Hence, the Framework can be used as a conceptual framework to facilitate or assist in the planning of a research study by presenting all of the relevant 
(A)
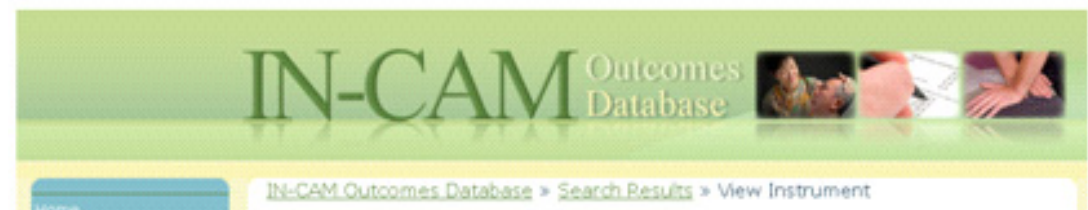

Wellness Evaluation of Lifestyle

Fremework:

7 Pbocit Us

War ousto

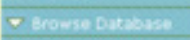

Alraneeda Sexch

Bitcuttion Eours

Setrbuten de sesod

Dutcome Nasure

clastary

pas

contuat us

Cupsest an cutesme

Gucsess or there

Search for Outcom

Mearch for Out
Measures

Ouick Seasch

fiog-

Logln

ivecas Username:

Mcas usamame:

N-CAMPassword

froshat

to reguter for an IN-Cand

user narte and

password, clease vist

Rate this Instrument

00000

Corrent Rating: $0.0 / 5$ ( 0 votes eant)

Print this Pesoed.

Basic Details

Extended Details User Comments

1 General Infermation

tastrumest Tite weliness Evaluasion ef Lidestre

Devcription The Welineis Evaluation of Lientive (WLL) outcome meatures is a

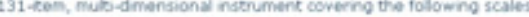

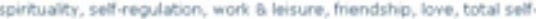
elegulatoon, perceverd watiness, and toty melines:

2 Hivtary

Comtributor

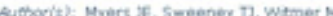

new cousted: 1996

3 Cost

Cost Prieng varies acoseding to number bougt, workbooks, on tine versions are also avalabie.

4 Classification

Damain Holatec

Basc to Teg

(B)
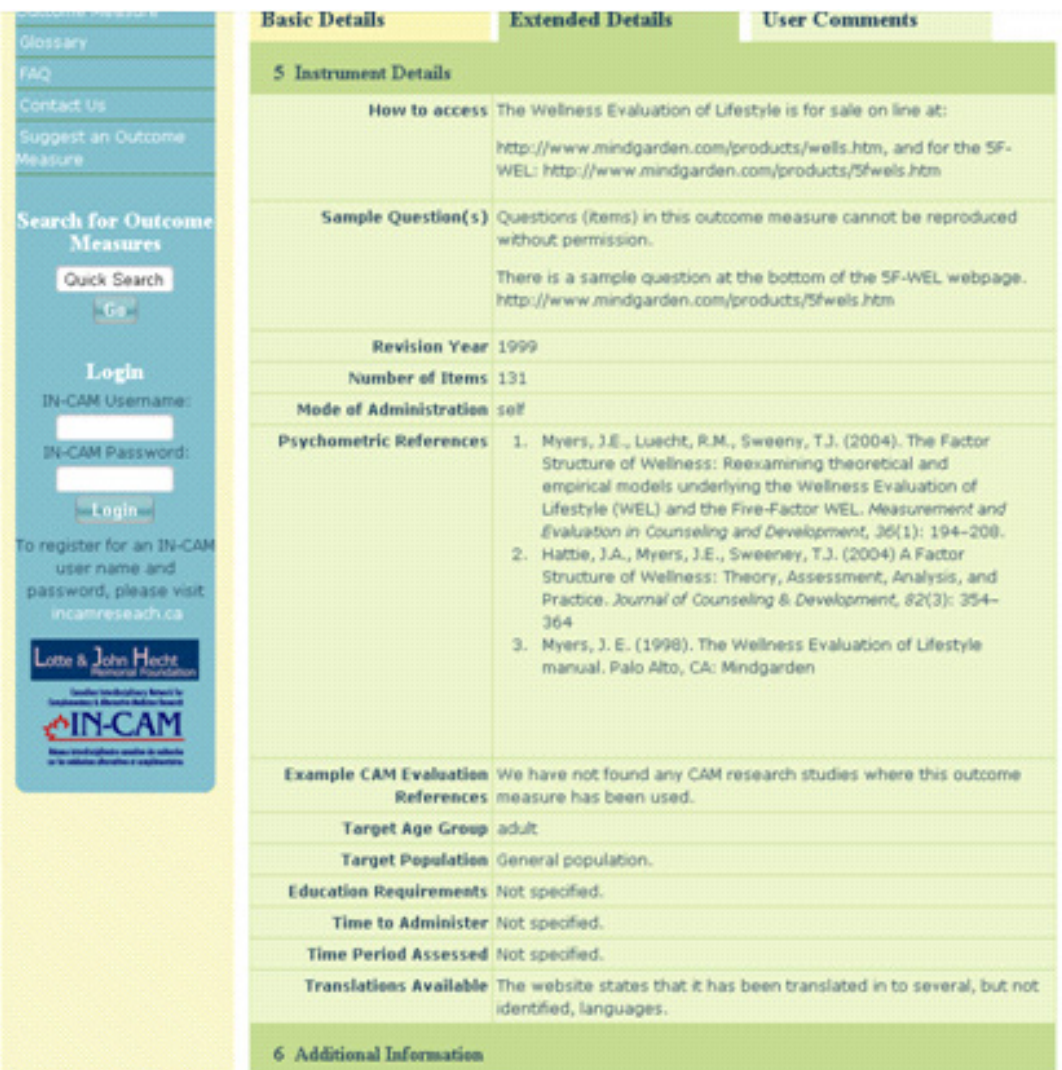

FIGURE 6. Information on outcome measures provided in the IN-CAM Outcomes Database under (A) "basic" and (B) "extended" details. 
domains that could be considered to fully assess the effectiveness or impact of an intervention.

Table 3 presents a research-oriented scenario that may be applicable to a researcher developing a study or to a massage therapist undertaking practice-based research (a case study or case series) to document the effects of MT.

\section{CREATING AN INTERACTIVE CAM RESEARCH COMMUNITY}

In addition to being an information resource on outcome measures, the IN-CAM Outcomes Database website has been designed to be an interactive tool. Several features have been built into the website to facilitate the exchange and dissemination of ideas, findings, and information related to outcomes assessment in CAM field. Discussions on topics of interest related to outcomes assessment and CAM can be initiated by users on the Discussion Board. For example, a massage therapist finds that many of her clients report a sense of "lightness" after a massage. She is not sure what this means, why it may be important to the clients, or how to effectively capture the experience. To highlight this unique outcome and to obtain feedback or ideas on potentially useful outcome measures to adequately assess it, she could start a discussion thread on the Discussion Board, engaging other practitioners and researchers in this exploratory phase. This exploration may lead not only to a discussion about identifying new and relevant outcomes in the massage field, but also to further exploration by researchers and, potentially, to the development of a new outcome measure.

Users also have an opportunity to post comments and a rating for each outcome measure in the Database. Users are invited to post comments and provide personal ratings of outcome measures based on their experience with those specific measures in research or practice. A common rating of outcome measures or their psychometric qualities is not provided through the Database website.

The Database will continue to be populated with relevant outcome measures as those measures are identified and developed. Members of the CAM research and practice community are therefore invited to contribute to the resources made available in the Database by submitting outcome measures through the Suggest an Outcome Measure feature of the website. All submissions are reviewed by an internal review committee for appropriateness. If accepted, the measure and its related information will be posted within 1 month of submission.

\section{CONCLUSIONS}

The use of outcome measures is an essential part of any type of activity that aims to evaluate a treatment or a health care intervention. As the MT profession continues to evolve and move toward evidence-informed practice, the application of outcome measures in research and practice is becoming increasingly important. It is imperative that massage therapists recognize that statements such as "that felt good" or "I feel better" from a client after a massage intervention is not enough to determine or measure the effect of the MT intervention. Although personal statements may be a starting point, identifying and using relevant outcomes is crucial in capturing client responses in a standardized way. An understanding of outcome measures, how they are applied in research and in practice, and which ones are relevant to MT practice is therefore also crucial. Research on massage interventions has to incorporate not only appropriate outcome measures, but also the range of health domains relevant to MT so as to fully explore and capture the outcomes of MT interventions. To that end, the IN-CAM Outcomes Database website is a valuable resource that can assist MT researchers and massage therapists in identifying

TABLE 3 Example: Applying the Framework to Research

In undertaking a study on the effects of massage therapy (MT) after a knee replacement surgery, the physical changes related to the degree of swelling and pain are both important outcomes. Referring to the Framework of Outcome Domains, other domains that may be important to consider in researching the effects of MT is Context of the intervention and Individualized outcomes (Fig. 2). The relationship between the patient and the massage therapist, the patient's expectations of MT, and the intention with which the massage therapist approaches the treatment may all affect the overall effectiveness of MT in reducing the swelling and pain levels in different patients.

Browsing the Context domain, a number of measures that aim to capture the effects of these contextual factors can be identified, as such the Consultation and Relational Empathy Measure ${ }^{(20)}$ and Complementary and Alternative Medicine Beliefs Inventory ${ }^{(21)}$. Although outcomes related to pain and swelling are important and likely to be the primary focus of the effectiveness of the MT intervention, the goals and concerns identified by the individual are equally important and require consideration. By considering individualized outcome measures listed in the Individualized domain, important outcomes of the massage intervention that would have otherwise been missed or not recognized may be identified.

For example, an individual may indicate that pain in the low back (because of a compensatory gait resulting from knee surgery) is of greater significance to them than is the affected knee. Without incorporating the goals or concerns of the individual, this outcome would have been overlooked and not have been considered to be one of the relevant or meaningful outcomes of MT after a knee replacement surgery. 
relevant and appropriate outcome measures, in obtaining access information for outcome measures, in conceptualizing research questions and studies, and in communicating with various stakeholders within the CAM research and practice community.

\section{CONFLICT OF INTEREST NOTIFICATION}

The author declares that there are no conflicts of interest.

\section{COPYRIGHT}

Published under the Creative Commons AttributionNonCommercial-NoDerivs 3.0 License.

\section{REFERENCES}

1. Esmail N. Complementary and Alternative Medicine in Canada: Trends in Use and Public Attitudes, 1997-2006. Public Policy Sources series, no. 87. A Fraser Institute occasional paper. Vancouver, BC: Fraser Institute; 2007: 3-53.

2. Barnes PM, Bloom B, Nahrin RL. Complementary and Alternative Medicine Use Among Adults and Children: United States, 2007. CDC National Health Statistics Report no. 12. Hyattsville, MD: U.S. Department of Health and Human Services, Centers for Disease Control and Prevention, National Center for Health Statistics. http:// nccam.nih.gov/news/2008/nhsr12.pdf. Accessed January 29, 2009.

3. Furlan AD, Brosseau L, Imamura M, Irvin E. Massage for lowback pain: a systematic review within the framework of the Cochrane Collaboration Back Review Group. Spine. 2002;27(17):1896-1910.

4. Ezzo J, Haraldsson BG, Gross AR, Myers CD, Morien A, Goldsmith CH, et al. on behalf of the Cervical Overview Group. Massage for mechanical neck disorders: a systematic review. Spine. 2007;32(3):353-362.

5. Moyer CA, Rounds J, Hannum JW. A meta-analysis of massage therapy research. Psychol Bull. 2004;130(1):3-18.

6. Verhoef MJ, Vanderheyden LC, Dryden T, Mallory D, Ware MA. Evaluating complementary and alternative medicine interventions: in search of appropriate patient-centered outcome measures. BMC Complement Altern Med. 2006;6(Nov 21):6-38.

7. United States, National Institutes of Health, National Center for Complementary and Alternative Medicine (NCCAM). Health Info > What is CAM? NCCAM website. http:// nccam.nih.gov/health/whatiscam/overview.htm. Updated February 26, 2009. Accessed February 27, 2009.

8. Canadian Interdisciplinary Network for Complementary and Alternative Medicine Research (IN-CAM). About Us > Mission \& Objectives. IN-CAM website. http://www.incamresear ch.ca/index.php?id=12,0,0,1,0,0\&menu=1. Updated February 18, 2009. Accessed February 27, 2009.

9. Verhoef MJ, Ware M, Dryden T, Gignac P, Weeks L, Kania A, et al. Getting the measures you need: the IN-CAM Outcomes Database. Focus Altern Complement Med Ther. 2007;12:170-171.

10. IN-CAM Outcomes Database. IN-CAM Outcomes Database $>$ Welcome [home page]. IN-CAM Outcomes Database website. http://www.outcomesdatabase.org. Published n.d. Accessed February 2, 2009.

11. MYMOP (Measure Your Own Medical Profile). Welcome to MYMOP [home page]. MYMOP website. http://www.pms.ac. uk/mymop/. Published n.d. Accessed January 29, 2009.

12. Paterson C. Measuring outcomes in primary care: a patient generated measure, MYMOP, compared with the SF-36 health survey. BMJ. 1996;312(7037):1016-1020.

13. Paterson C, Britten N. In pursuit of patient-centred outcomes: a qualitative evaluation of the "Measure Yourself Medical Outcome Profile." J Health Serv Res Policy. 2000;5(1):27-36.

14. Moyer CA, Rounds J. The Attitudes Toward Massage (ATOM) scale: reliability, validity, and associated findings. $J$ Bodyw Move Ther. 2009;13(1):22-33.

15. IN-CAM Outcomes Database. IN-CAM Outcomes Database $>$ View Instrument $>$ Measure Your Transformative Outcome Profile (MYTOP). IN-CAM Outcomes Database website. http://www.outcomesdatabase.org/show/element/id/274. Published n.d. Accessed January 29, 2009.

16. Brantley PJ, Waggoner CD, Jones GN, Rappaport NB. A Daily Stress Inventory: development, reliability, and validity. J Behav Med. 1987;10(1):61-74.

17. Bell IR, Cunningham V, Caspi O, Meek P, Ferro L. Development and validation of a new global well-being outcomes rating scale for integrative medicine research. BMC Complement Altern Med. 2004;4(Jan 15):1.

18. Hattie JA, Myers JE, Sweeney TJ. A factor structure of wellness: theory, assessment, analysis, and practice. J Couns Dev. 2004;82(3):354-364.

19. IN-CAM Outcomes Database. IN-CAM Outcomes Database $>$ View Instrument $>$ COOP Wonca Charts. IN-CAM Outcomes Database website. http://www.outcomesdatabase.org/show/element/id/481. Published n.d. Accessed February 5, 2009.

20. Mercer SW, Maxwell M, Heaney D, Watt GC. The Consultation and Relational Empathy (CARE) measure: development and preliminary validation and reliability of an empathy-based consultation process measure. Fam Pract. 2004;21(6):699-705.

21. Bishop FL, Yardley L, Lewith G. Developing a measure of treatment beliefs: the Complementary and Alternative Medicine Beliefs Inventory. Complement Ther Med. 2005;13(2):144-149.

Corresponding author: Ania Kania,University of Calgary, Department of Community Health Sciences, 3330 Hospital Drive NW, Room G-26,Calgary, AB T2N 4N1 Canada.

E-mail: akania@ucalgary.ca 